\title{
Comprehensive study of insomnia and its association with specific burn characteristics: an experience from a tertiary care centre in North-West India
}

\author{
Rakesh Kumar Jain ${ }^{1}$, Gautam Prakash ${ }^{1}{ }^{*}$, Manojit Midya $^{1}$, Pankaj Sharma ${ }^{1}$, Akhilesh Jain ${ }^{2}$
}

${ }^{1}$ Department of Burns and Plastic Surgery, SMS Medical College, Jaipur, Rajasthan, India

${ }^{2}$ Department of Psychiatry, ESIC Model Hospital, Jaipur, Rajasthan, India

Received: 03 July 2018

Revised: 25 July 2018

Accepted: 26 July 2018

\author{
*Correspondence: \\ Dr. Gautam Prakash, \\ E-mail: drgprakash86@gmail.com
}

Copyright: ( the author(s), publisher and licensee Medip Academy. This is an open-access article distributed under the terms of the Creative Commons Attribution Non-Commercial License, which permits unrestricted non-commercial use, distribution, and reproduction in any medium, provided the original work is properly cited.

\begin{abstract}
Background: Burn injuries are devastating, sudden and unpredictable forms of trauma which affect the victims both physically and psychologically. Recent advances in medical management have drastically decreased mortality rates of burn patients. There is a significant relationship between acute burn pain and sleep. Alteration in sleep patterns are commonly seen in post burn patients. The objectives of the study were to determine the prevalence of insomnia in burn patients compared with a group of adequately matched controls; to determine risk factors associated with insomnia; to study the quality of sleep in post burn patients compared with a group of adequately matched controls.

Methods: Sleep quality in post burn patients was analyzed and measured with the help of Pittsburg sleep quality index questionnaire and compared with a group of adequately matched controls. Post burn patients experienced prolonged and long lasting pain which is assessed with visual analogue scale. Data were tabulated and analyzed statistically using univariate and multivariate analysis (chi square test, odds ratio, Binary logistic regression).

Results: The relationship between post burn patients with changed sleep architecture and pain was found to be statistically significant. Other important parameters were also evaluated and discussed.

Conclusions: Post burn patients are more prone for disturbed sleep patterns. Any variation in sleep patterns and quality is significantly related to pain experienced by the post burn patients, thus this problem should be evaluated and analyzed meticulously.
\end{abstract}

Keywords: Burn injury, PSQI questionnaire, VAS, Sleep architecture

\section{INTRODUCTION}

Burn injuries are devastating, sudden and unpredictable forms of trauma which affect the victims both physically and psychologically. ${ }^{1}$ Recent advances in medical management have drastically decreased mortality rates of burn patients. ${ }^{2}$ Sleep disturbances are commonly found in hospitalized patients. ${ }^{3-7}$ These changes in sleep patterns have negative effect on various phases of rehabilitation. ${ }^{8}$ Alteration in sleep pattern is responsible for undesirable metabolic changes that occur after a major burn. ${ }^{9}$
Sleep problems are commonly found after burn injury. ${ }^{10}$ Endogenous factors like acetylcholine, serotonin, neuropeptides and exogenous factors like stress and pain have been proposed as potential causes for sleep disturbance. ${ }^{11}$ Although very few of these possibilities have been thoroughly studied, pain appears to be an important factor and has been reported as being the principal cause of sleep disturbances in hospitalized populations. $^{12}$ 
Moreover, a significant daily relationship between burn pain and sleep has been observed where higher pain intensity leads to poor sleep, which in turn, affects quality of sleep. Further, it is suggested that this vicious cycle may worsen over time, since prolonged pain could lead to further exacerbation of sleep disturbances, which have been reported up to one year after hospital discharge. ${ }^{13,14}$

The assumption that post-burn injury patients are potential candidates in whom such disturbances may be present is highly relevant. Even then, studying the quality and patterns of sleep in post burn patients appears to remain unexplored by the burn care physician. Therefore, this study was conducted with the aim to determine the prevalence of insomnia in burn patients compared with a group of adequately matched controls and to identify risk factors associated with insomnia.

\section{METHODS}

The present study was a hospital based, observational, cross sectional study involving 434 burn patients who were admitted to burn ward of Plastic and Reconstructive Surgery in Sawai Man Singh Hospital Jaipur or came for follow up, between February 2015 to January 2017. The inclusion criteria were: $>15$ years of age; absence of any sleep-related problems before burn injury, as described by the patient including history of sleep apnea; individuals without jobs involving night shifts or excessive travel; absence of co-morbid conditions that can cause altered sleep patterns such as chronic asthma, chronic obstructive pulmonary disease, obesity, alcohol addiction and no previous use of sleep-inducing or sedative medications.

Total 200 burn patients were found to be eligible. Equal number $(n=200)$ of age and sex matched healthy participants from family or close relatives included in the study to serve as control group.

Quality and pattern of sleep was evaluated by using the Pittsburgh sleep quality index (PSQI) questionnaire during the hospital stay of the patient and on OPD follow up basis. ${ }^{15-17}$ In adult population PSQI questionnaire is an efficient and valid tool to measure the quality and patterns of sleep. Each question in PSQI questionnaire is scored on a scale 0 to 3 , in this scale 3 indicates negative extreme on 'Likert scale'. Score $>5$ reflects poor sleep of a patient.

The PSQI questionnaire is a subjective measure of sleep. Psychometric properties of the PSQI have been examined and found to be appropriate with regard to internal consistency concurrent validity and discriminative validity in healthy and ill populations. ${ }^{14-16}$

The PSQI questionnaire has internal consistency and a reliability coefficient (Cronbach's alpha) of 0.83 for its seven components. This questionnaire is used in different studies in older as well as in adult populations and have gained internationally high validity and reliability.

Pain intensity in a burn patient was measured with the help of visual analogue scale (VAS). ${ }^{1}$ VAS is a straight horizontal line of fixed length, usually $100 \mathrm{~mm}$. The ends are defined as the extreme limits of the parameter to be measured (symptom, pain, health) orientated from the left (worst) to the right (best).

Using a ruler, the score is determined by measuring the distance $(\mathrm{mm})$ on the $10-\mathrm{cm}$ line between the "no pain" anchor and the patient's mark, providing a range of scores from 0-100. A higher score indicates greater pain intensity as none, mild, moderate, or severe. The following cut points on the pain VAS have been recommended: no pain $(0-4 \mathrm{~mm})$, mild pain $(5-44 \mathrm{~mm})$, moderate pain $(45-74 \mathrm{~mm})$, and severe pain (75-100 $\mathrm{mm})$.

Socio demographic and burn characteristics of the patients were recorded in semi structured proforma. (Table 1).

Statistical analysis was done in SPSS statistical software (Trial version 23). Univariate analysis done by using odds ratio (95\% Confidence interval) chi square test and multivariate analysis done by using Binary logistic regression).

\section{RESULTS}

Total 434 patients were included in study sample out of which 200 patients were found to be eligible for this study. During the hospital stay and on OPD follow up, patients were interviewed as per PSQI questionnaire and asked to describe their sleep quality and pattern before and after the burn injury and compared accordingly.

Socio demographic and burn characteristics of the patients is shown in Table 1. 58\% $(n=116)$ of burn patients reported PSQI score $>5$ as compared to $38.5 \%$ $(n=67)$ of the control group who scored $>5$ on PSQI questionnaire (Table 2).

Among burn patients who scored $>5$ on PSQI, 68 $(58.62 \%)$ were male and $48(41.38 \%)$ were female. Most of these patients had TBSA of $>20 \%$ with upper half of body were involved in 166 patients $(83 \%)$, and lower half of body in 34 patients (17\%). Flame burns was the most common type of burn (63\%), followed by electrical burns $(25 \%)$ and scald burns (12\%) respectively in decreasing order of occurrence.

Further analysis of the PSQI questionnaire revealed that the most troublesome aspects of patients' sleep were: difficulty in falling asleep due to increased time period for initiation of sleep; falling asleep difficult; nightmares; small intervals of sleep intervened by frequent awakening episodes and difficulty in breathing in facial burn patients. 
Table 1: Socio-demographic and burn characteristics of patients.

\begin{tabular}{|c|c|c|c|}
\hline Age & Mean \pm SD (range) & $30.96 \pm 12.41$ ( 9 to 5 & \\
\hline & & Number of patients & $\%$ \\
\hline \multirow{2}{*}{ Age groups } & $<30$ & 102 & 51 \\
\hline & $\geq 30$ & 98 & 49 \\
\hline \multirow{2}{*}{ Sex } & Female & 82 & 41 \\
\hline & Male & 118 & 59 \\
\hline \multirow{5}{*}{ SES (1-5) } & I & 84 & 42 \\
\hline & II & 32 & 16 \\
\hline & III & 36 & 18 \\
\hline & IV & 22 & 11 \\
\hline & V & 26 & 13 \\
\hline \multirow{2}{*}{ Occupation } & Employed & 56 & 28 \\
\hline & Unemployed & 144 & 72 \\
\hline \multirow{3}{*}{ Education } & Illiterate & 38 & 19 \\
\hline & Literate & 102 & 51 \\
\hline & Semiliterate & 60 & 30 \\
\hline \multirow{2}{*}{ PSQI } & $<5$ & 84 & 42 \\
\hline & $>5$ & 116 & 58 \\
\hline \multirow{4}{*}{ VAS } & 0 & 42 & 21 \\
\hline & 1 & 50 & 25 \\
\hline & 2 & 64 & 32 \\
\hline & 3 & 44 & 22 \\
\hline \multirow{3}{*}{ TBSA (\%) } & $<10 \%$ & 64 & 32 \\
\hline & $10-20 \%$ & 54 & 27 \\
\hline & $>20 \%$ & 82 & 41 \\
\hline \multirow{3}{*}{ Duration } & $<1$ month & 76 & 38 \\
\hline & $>3$ month & 66 & 33 \\
\hline & 1-3 month & 58 & 29 \\
\hline \multirow{3}{*}{ Mode of injury } & Electric & 50 & 25 \\
\hline & Flame & 126 & 63 \\
\hline & Scald & 24 & 12 \\
\hline \multirow{2}{*}{ Region involved } & Lower trunk & 34 & 17 \\
\hline & Upper trunk & 166 & 83 \\
\hline
\end{tabular}

*SES-Socio-economic status, TBSA-Total body surface area, VAS- visual analogue scale [group 0 (0-4mm) - no pain, group 1 (5$44 \mathrm{~mm}$ )-mild pain, group 2 (45-74mm)- moderate pain and group 3 (75-100mm)-severe pain], PSQI-Pittsburg sleep quality index.

Table 2: Significance of Pittsburg sleep quality index (PSQI) values in post burn patients versus non burn patients.

\begin{tabular}{|lll|}
\hline & Post burn patients $(\mathbf{n}=\mathbf{2 0 0})$ & Non burn patients $(\mathbf{n}=\mathbf{2 0 0})$ \\
\hline PSQI score $<\mathbf{5}$ & 84 & 133 \\
\hline PSQI score $>\mathbf{5}$ & 116 & 67 \\
\hline
\end{tabular}

PSQI-Pittsburg sleep quality index.

Socio demographic and burn characteristics were also correlated with sleep problems in study sample. In univariate analysis, VAS, TBSA, and duration of burn were observed significant predictors for PSQI $>5$ risk factors. VAS score 2 to 3 was 28.8 times more associated as risk factor of insomnia as compared to VAS 1-2 as Odds Ratio was 28 (95\% confidence interval: 13.226 to 62.713) $\mathrm{p}<0.001 \mathrm{~S}$.

Likewise TBSA (>20\%) was 12.8 times more associated as risk factor of insomnia as compared to TSBA $(<10 \%)$ as Odds ratio was 12.833 (95\% confidence interval: 5.715 to 28.818$) \mathrm{p}<0.001 \mathrm{~S}$.

With regard to duration of burn (1-3 months) and $(<1$ months) had 3.76 and 8.625 times respectively more risk of insomnia as compared to duration of burn (>3 months) as odds ratio was 3.764 (95\% confidence interval: 1.784 to 7.938 ) and 8.625 (95\% confidence interval: 4.028 to 18.468) $\mathrm{p}<0.001 \mathrm{~S}$ (Table 3 ). 
Table 3: Univariate analysis of PSQI >5 risk factors.

\begin{tabular}{|c|c|c|c|c|c|c|c|}
\hline & & \multicolumn{2}{|c|}{ PSQI >5 (N=116) } & \multicolumn{2}{|c|}{ PSQI $<5(\mathrm{~N}=84)$} & \multirow{2}{*}{$\begin{array}{l}\text { Odds ratio ( } 95 \% \\
\text { confidence interval) }\end{array}$} & \multirow{2}{*}{$P$ value $\mathrm{LS}$} \\
\hline & & No & $\%$ & No & $\%$ & & \\
\hline \multirow{2}{*}{ Age } & $<30$ & 66 & 56.9 & 36 & 42.86 & $1.760(0.998$ to 3.104$)$ & \multirow{2}{*}{$0.069 \mathrm{NS}$} \\
\hline & $\geq 30$ & 50 & 43.1 & 48 & 57.14 & Ref & \\
\hline \multirow{2}{*}{ Sex } & Female & 48 & 41.38 & 34 & 40.48 & $1.038(0.586$ to 1.838$)$ & \multirow{2}{*}{$0.98 \mathrm{NS}$} \\
\hline & Male & 68 & 58.62 & 50 & 59.52 & Ref & \\
\hline \multirow{2}{*}{$\operatorname{SES}(\mathbf{I}-\mathbf{V})$} & Lower & 28 & 24.14 & 20 & 23.81 & $1.018(0.527$ to 1.966$)$ & \multirow{2}{*}{$0.90 \mathrm{NS}$} \\
\hline & upper & 88 & 75.86 & 64 & 76.19 & Ref & \\
\hline \multirow{2}{*}{ Occupation } & Unemployed & 86 & 74.14 & 58 & 69.05 & $1.285(0.690$ to 2.393$)$ & \multirow{2}{*}{$0.53 \mathrm{NS}$} \\
\hline & Employed & 30 & 25.86 & 26 & 30.95 & Ref & \\
\hline \multirow{2}{*}{ Education } & Literate & 96 & 82.76 & 66 & 78.57 & 1.309 (0.644 to 2.662$)$ & \multirow{2}{*}{$0.57 \mathrm{NS}$} \\
\hline & Illiterate & 20 & 17.24 & 18 & 21.43 & Ref & \\
\hline \multirow{2}{*}{ VAS } & 2 to 3 & 96 & 82.76 & 12 & 14.29 & $28.800(13.226$ to 62.713$)$ & \multirow{2}{*}{$<0.001 \mathrm{~S}$} \\
\hline & $0-1$ & 20 & 17.24 & 72 & 85.71 & Ref & \\
\hline \multirow{3}{*}{ TBSA (\%) } & $<10 \%$ & 20 & 17.24 & 44 & 52.38 & Ref & \\
\hline & $10-20 \%$ & 26 & 22.41 & 28 & 33.33 & $2.043(0.964$ to 4.330$)$ & $0.092 \mathrm{NS}$ \\
\hline & $>20 \%$ & 70 & 60.34 & 12 & 14.29 & $12.833(5.715$ to 28.818$)$ & $<0.001 \mathrm{~S}$ \\
\hline \multirow{3}{*}{ Duration } & $>3$ months & 20 & 17.24 & 46 & 54.76 & Ref & \\
\hline & 1-3 months & 36 & 31.03 & 22 & 26.19 & $3.764(1.784$ to 7.938$)$ & $<0.001 \mathrm{~S}$ \\
\hline & $<1$ months & 60 & 51.72 & 16 & 19.05 & 8.625 (4.028 to 18.468$)$ & $<0.001 \mathrm{~S}$ \\
\hline \multirow{3}{*}{$\begin{array}{l}\text { Mode of } \\
\text { injury }\end{array}$} & Scald & 12 & 10.34 & 12 & 14.29 & Ref & \\
\hline & Electrical & 30 & 25.86 & 20 & 23.81 & $1.500(0.563$ to 3.997$)$ & $0.575 \mathrm{NS}$ \\
\hline & Flame & 74 & 63.79 & 52 & 61.9 & $1.423(0.593$ to 3.415$)$ & $0.57 \mathrm{NS}$ \\
\hline \multirow{2}{*}{$\begin{array}{l}\text { Region } \\
\text { involved }\end{array}$} & Lower trunk & 18 & 15.52 & 16 & 19.05 & $0.781(0.372$ to 1.638$)$ & $0.64 \mathrm{NS}$ \\
\hline & Upper trunk & 98 & 84.48 & 68 & 80.95 & Ref & \\
\hline
\end{tabular}

PSQI-Pittsburg Sleep Quality Index, SES- socio-economic status, VAS- Visual Analogue Scale, TBSA- Total body surface area,

Table 4: Predictors for insomnia by using binary logistic regression (Multivariate analysis).

\begin{tabular}{|c|c|c|c|c|}
\hline \multirow{2}{*}{ Variables } & \multirow{2}{*}{$\operatorname{Exp}(B)$} & \multicolumn{2}{|c|}{$95 \%$ CI for EXP (B) } & \multirow{2}{*}{ Sig. } \\
\hline & & Lower & Upper & \\
\hline Age (<30 vs. >30) & 1.668 & 0.434 & 6.408 & $0.457 \mathrm{NS}$ \\
\hline Sex (male vs. female) & 0.875 & 0.232 & 3.303 & $0.844 \mathrm{NS}$ \\
\hline SES (upper) & 1.493 & 0.309 & 7.213 & $0.618 \mathrm{NS}$ \\
\hline VAS & 150.808 & 22.351 & 1017.538 & $<0.001 \mathrm{~S}$ \\
\hline Occupation- employed vs. unemployed & 1.553 & 0.419 & 5.751 & $0.510 \mathrm{NS}$ \\
\hline Education (1) & 0.130 & 0.019 & 0.900 & $0.059 \mathrm{NS}$ \\
\hline TBSA $<10 \%$ & Ref & & & \\
\hline $10-20 \%$ & 0.016 & 0.002 & 0.109 & $<0.001 \mathrm{~S}$ \\
\hline$>20 \%$ & 0.027 & 0.004 & 0.176 & $<0.001 \mathrm{~S}$ \\
\hline Duration >3 months & Ref & & & \\
\hline 1-3 months & 30.393 & 2.921 & 316.274 & $0.004 \mathrm{~S}$ \\
\hline$<1$ months & 15.823 & 1.749 & 143.112 & $0.014 \mathrm{~S}$ \\
\hline \multicolumn{5}{|l|}{ Region (lower trunk) } \\
\hline Upper trunk (Ref) & 0.620 & 0.120 & 3.197 & 0.568 \\
\hline Mode of injury scald (Ref) & & & & 0.771 \\
\hline Electrical & 0.870 & 0.117 & 6.445 & 0.892 \\
\hline Flame & 1.634 & 0.369 & 7.243 & 0.518 \\
\hline
\end{tabular}

SES- socioeconomic status, VAS- Visual analogue scale, TBSA- Total body surface area.

A logistic regression analysis was also done to predict insomnia for 200 patients using the age, sex, Socioeconomic status, occupation, education, VAS, TBSA, duration of burn, mode of burn and region involved as predictors. A test of full model was statistically significant indicating that the predictors as asset, reliably distinguish between insomnia happening or not (Chi square 191.073, df 13, p<0.001). Also, the 
Hosmer and Lemshow test showed a good fit by high $\mathrm{p}$ value and low Chi square value. (Chi square 4.485, df 8 , $\mathrm{p}=0.811$ ). Negel Kerke $\mathrm{R}^{2}$ of 0.828 indicated good relationship between predictors and grouping. The Wald criteria demonstrated that VAS, TBSA, duration of burn $(\mathrm{p}<0.05 \mathrm{~S})$ made a significant contribution to prediction. Other predictors were not significant (Table 4).

\section{DISCUSSION}

Sleep pattern is an important and integral part of post burn rehabilitation. Poor sleep quality may have several negative effects on physical and mental health. It may cause increased fatigue, poor concentration, irritability, anxiety and depression. ${ }^{18,19}$ Poor sleep adversely affects immune, neuroendocrine and metabolic functions. ${ }^{4}$ It activates hypothalamic pituitary adrenal (HPA) axis chronically which increases mortality risk. ${ }^{20}$

Sleep disturbances are frequently reported by burn patients. ${ }^{21}$ However, this area has not been given much attention. This study was aimed to identify sleep pattern in burn patients and also to explore burn characteristics associated with abnormal sleep.

In our study population, burn patients had poor sleep quality as measured on PSQI, compared to control group. Masoodi et al has also reported significant poor sleep quality in $61.24 \%$ patients assessed on PSQI in his study of 818 post burn patients. ${ }^{2}$ Similar observation has been made in yet another study by Raymond who reported poor night time sleep in terms of duration and fragmentation in hospitalized burn patients. ${ }^{6}$

Total burn surface area (TBSA) was associated with poor sleep quality. In a recent study, it was stated that patients had greater sleep disturbances in those who had TBSA of 20 to $40 \% .^{2}$ Larger burn surface area may give rise to long lasting pain of higher intensity leading to frequent sleep problems. There is more chance of contractures and disfigurement with larger TBSA, thus causing more emotional and psychological consequences which may further aggravate in poor sleep quality. ${ }^{2}$ It has also been observed that patients with larger TBSA tend to stay in hospital for longer period and increased hospital stay has also been reported to be associated with derangement in sleep architecture. ${ }^{1}$ It is further suggested that sleep disturbance following burns was significantly associated with increasing burn size. ${ }^{18}$ Similarly to the above studies, our findings also show sleep disturbances to be more prevalent in burn patients who had TBSA more than $20 \%$. The association was found to be statistically significant (Table 3).

Another important finding of our study was significant association $(\mathrm{p}<0.001)$ between pain intensity and sleep quality in post burn patients. Several other studies have also reported similar findings suggesting close association between burn pain and sleep abnormalities. ${ }^{11,12}$ Further, the pain intensity can aggravate over the course of treatment as new therapeutic interventions take precedence. ${ }^{22,23}$ An association between acute burn pain and sleep have been suggested where poor sleep leads to experience higher intensity pain which in return gives rise to poor quality of sleep. This vicious cycle gets worse over time and causes further exacerbation of sleep disturbances. ${ }^{11,12}$

Duration of burn in this study was also significantly associated with poor sleep quality. Shorter post burn period (1-3 month) was more associated with sleep disturbances than the longer post burn duration (>3 months). Pain intensity and associated emotional and psychological components are more intensified in first few weeks after burn injury. ${ }^{6}$ These factors have been implicated to cause poor sleep quality in other studies. ${ }^{24}$ Furthermore, it has found in other studies also that patients who are hospitalized for longer duration irrespective of their diagnosis suffer from sleep disturbance. $^{25}$ In our study, we found that as the wound size decreased with time, the pain intensity also diminished proportionately. This decreased pain intensity over time reduced the likelihood of associated sleep disturbances. Further, burn patients are hospitalized for first few weeks and hospital stay has again been reported to perpetuate sleep disturbances. ${ }^{5,6}$

\section{CONCLUSION}

The objective of present study was to find out the prevalence of change in sleep quality and sleep patterns in post burn patients. Burn patients had remarkably frequent sleep problems as compared to normal controls. In this study, sleep disturbances were closely associated with certain burn characteristics including TBSA, duration of burn, associated pain intensity. Addressing the sleep problems in such patients may be significantly helpful in management of acute phase as well as rehabilitation.

Funding: No funding sources

Conflict of interest: None declared

Ethical approval: The study was approved by the Institutional Ethics Committee

\section{REFERENCES}

1. Roberts RE, Shema SJ, Kaplan GA, Strawbridge WJ. Sleep complaints and depression in an aging cohort: A prospective perspective. Am J Psychiatry. 2000;157(1):81-8.

2. Masoodi Z, Ahmad I, Khurram F, Haq A. Changes in sleep architecture after burn injury: 'Waking up' to this unaddressed aspect of post burn rehabilitation in the developing world. Can J Plast Surg. 2013;21(4):234-8.

3. Wooten V. Medical causes of insomnia. In: Wooten $\mathrm{V}$, editor. Principles and practice of sleep medicine. Philadelphia: W.B. Saunders Company; 1994: 509522 . 
4. Rosenberg-Adamsen S, Kehlet H, Dodds C, Rosenberg J. Postoperative sleep disturbances: mechanisms and clinical implications. Br J Anaesth. 1996;76:552-9.

5. Redeker NS. Sleep in acute care settings: an integrative review. J Nurs Scholarsh. 2000;32(1):31-8.

6. Raymond I, Nielsen TA, Lavigne G, Manzini C, Choiniere M. Quality of sleep and its daily relationship to pain intensity in hospitalized adult burn patients. Pain. 2001;92(3):381-8.

7. Rose M, Sanford A, Thomas C, Opp MR. Factors altering the sleep of burned children. Sleep. 2001;24(1):45-51.

8. RobertS RE, Shema SJ, Kaplan GA, Strawbridge WJ. Sleep complaints and depression in an aging cohort: A prospective perspective. Am J Psychiatry. 2000;157(1):81-8.

9. Wiechman-Askay S, Sharar S, Mason ST, Patterson D. Pain, Pruritis, and Sleep Following Burn Injury. Int J Psychiatry. 2009;21(6):522-30.

10. Jaffe SE, Patterson DR. Treating Sleep Prob $\neg$ lems in Patients with Burn Injuries: Practical Considerations. J Burn Care Rehabil. 2004;25(3):294-305.

11. Garciaa-Garciaa F, Drucker-Colian R. Endogenous and Exogenous Factors on Sleep - Wake Cycle Regulation. Progress Neurobiol. 1999;58:297-314.

12. Closs SJ. Patient's night-time pain, analgesic provision and sleep after surgery. Int J Nurs Stud. 1992;29(4):381-92.

13. Lawrence JW, Fauerbach J, Eudell E, Ware L, Munster A. The 1998 Clinical Research Award. Sleep disturbances after burn injury: a frequent yet understudied complication. J Burn Care Rehabil. 1998;19(6):480-6.

14. Boeve SA, Aaron LA, Martin-Herz SP, Peterson A, Cain V, Heimbach DM, Patterson DR. Sleep disturbances after burn injury. J Burn Care Rehabil. 2002;23(1):32-8.

15. Buysse DJ, Reynolds CF 3rd, Monk TH, Berman SR, Kupfer DJ. The Pittsburgh Sleep Quality Index:
A new instrument for psychiatric practice and research. Psychiatry Res. 1989;28:193-213.

16. Carpenter JS, Andrykowski MA. Psychometric evaluation of the Pittsburgh Sleep Quality Index. J Psychosom Res. 1998;45(1):5-13.

17. Backhaus J, Junghanns K, Broocks A, Riemann D, Hohagen F. Test-retest reliability and validity of the Pittsburgh Sleep Quality Index in primary insomnia. J Psychosom Res. 2002;53(3):737-40.

18. Konsman JP, Parnet P, Dantzer R. Cytokineinduced sickness behavior: Mechanisms and implications. Trends Neurosci. 2002;25(3):154-9.

19. Smith MT, Perlis ML, Smith MS, Giles DE, Carmody TP. Sleep quality and pre sleep arousal in chronic pain. J Behav Med. 2000;23(1):1-13.

20. Carmichael CL, Reis HT. Attachment, sleep quality, and depressed affect. Health Psychol. 2005;24(5):526-31.

21. Gabor JY, Cooper AB, Hanly PJ. Sleep disruption in the intensive care unit. Curr Opin Crit Care. 2001;7(1):21-7.

22. Meyer WJ, Marvin JA, Patterson DR. In: Herdon $\mathrm{DN}$, editor. Management of pain and other discomforts in burned patients. London: WB Saunders; 2002: 747-765.

23. Choiniere M. Pain of burns. In: Melzack R, Wall PD, editors. Handbook of pain management: a clinical companion to textbook of pain. London: Churchill Livingston; 2003: 591-601.

24. Raymond I, Ancoli-Israel S, Choiniere M. Sleep disturbances, pain and analgesia in adults hospitalized for burn injuries. Sleep Med. 2004;5(6):551-9.

25. Berlin RM, Management of Insomnia in Hospitalized Patients. Annals of Internal Medicine. 1984;100:398-404.

Cite this article as: Jain RK, Prakash G, Midya M, Sharma P, Jain A. Comprehensive study of insomnia and its association with specific burn characteristics: an experience from a tertiary care centre in North-West India. Int J Community Med Public Health 2018;5:3807-12. 